\title{
Facial Asymmetry Caused by Mandibular Osteoma: Case Report
}

\author{
Bruna Barcelos Ferreira ${ }^{1}$, Eduardo Stedile Fiamoncini' ${ }^{1}$ Caio Peres Bellato ${ }^{1}$, \\ Victor Tieghi Neto², Denise Tostes Oliveira², Osny Ferreira Junior², Eduardo Sanches Gonçales ${ }^{2 *}$ \\ ${ }^{1}$ Oral and Maxillofacial Surgery, Bauru School of Dentistry, São Paulo University, São Paulo, Brazil \\ ${ }^{2}$ Department of Surgery, Stomatology, Pathology and Radiology, Bauru School of Dentistry, São Paulo University, \\ São Paulo, Brazil \\ Email: *eduardogoncales@usp.br
}

How to cite this paper: Ferreira, B.B., Fiamoncini, E.S., Bellato, C.P., Neto, V.T., Oliveira, D.T., Ferreira Junior, O. and Gonçales, E.S. (2019) Facial Asymmetry Caused by Mandibular Osteoma: Case Report. Open Journal of Stomatology, 9, 208-214.

https://doi.org/10.4236/ojst.2019.99022

Received: August 1, 2019

Accepted: September 3, 2019

Published: September 6, 2019

Copyright $\odot 2019$ by author(s) and Scientific Research Publishing Inc. This work is licensed under the Creative Commons Attribution International License (CC BY 4.0).

http://creativecommons.org/licenses/by/4.0/ Open Access

\begin{abstract}
Osteoma is a benign tumor that often affects the maxillofacial region. It exhibits slow growth and remains asymptomatic for prolonged time and may cause facial asymmetry or functional disorders when it reaches vast proportions. When osteomalacia is diagnosed it is important to check about Gardner's Syndrome because up to $90 \%$ of patients with this syndrome may present skeletal abnormalities and osteomas. The objective of this paper is to report a case of a 54-year-old woman that related an 8-year evolution of a volume increase in the face. Clinical examination showed facial asymmetry and presence of nodular lesion located in the left region of the mandibule, painless and hard on palpation. Panoramic radiography showed radiopaque image limited to the left mandibular body and angle, suggestive of osteoma. Gastrointestinal review was requested and discarded intestinal polyps and Gardner's Syndrome. The patient was submitted to excisional biopsy and microscopic examination of the tumor that confirmed the diagnosis of osteoma. Osteoma needs special attention due to the possible association with malignant lesions intestine and also by psychological and functional problems, when it reaches great proportions.
\end{abstract}

\section{Keywords}

Osteoma, Oral Surgery, Mandibule

\section{Introduction}

Osteomas are benign neoplasms that show slow growing and often affect the maxillofacial region [1] [2] [3]. Since it remains asymptomatic for a long time, it usually causes facial asymmetry or functional disorders, which leads the patient 
to seek health service only when the tumours present great proportions and extensions [1] [2] [4]. The pathogenesis of this tumor is not well understood and it can be considered as a true neoplasm or a development disorder or a reactive mechanism due to trauma, infection or muscle pull [4] [5].

Patients with osteomas should be investigated about Gardner's Syndrome that is imposed by multiple osteomas, supernumerary teeth, gastrointestinal polyps, epidermoid cysts and dermoid tumours and the intestinal polyps can become malignant tumours [6] [7]. Radiographic images can be sufficient to diagnose the osteoma [2] [8]. However, for the surgical treatment (removal) of the lesion, a computed tomography is fundamental to planning and to execution of the surgery [2] [8].

The treatment of choice is surgical removal of the osteoma especially in cases of bigger size because it can generate patient discomfort [9] [10] [11]. The purpose of the present article is to report a case of facial asymmetry caused by mandibular osteoma of large proportion, that is justified by the interface between the osteoma and Gardner's Syndrome and by the importance of the diagnosis of Gardner's Syndrome, as well as the relevance of paths to the diagnosis, the unusual dimensions of the osteoma and the surgery to remove it.

\section{Case Report}

White woman, 54 years old, chief complain "a ball growth in her face", asymptomatic and 8 years of development. Progressive and slow growth caused a deformity in her face that led her to seek treatment at Bauru School of Dentistry, Brazil. There was no history of facial trauma or any other external cause to justify the growth.

The clinical examination showed facial asymmetry, presence of increased mass in body and angle of the left mandibular side, firm and painless on palpation and covered by normal skin (Figure 1). No regional lymphadenopathy was present and there wasn't report of paraesthesia. Intraoral examination showed increased mass, covered by normal mucosa (Figure 2) and radiographic examination showed radiopaque image in left portion of the mandible suggestive of osteoma (Figure 3). Cone beam computed tomography was performed and showed hyperdense mass, circumscribed, lobulated surface and measuring approximately $28 \times 20 \times 16 \mathrm{~cm}$ (Figure 4 ).

Evaluation of the intestinal tract was requested to rule out the hypothesis of Gardner's syndrome and no intestinal abnormalities were observed. The patient was submitted to excision under general anaesthesia through intra-oral approach at the region of the lesion, followed by periosteal detachment and total exposure of the lesion (Figure 5). Through the use of a sagittal saw, the osteomalacia was completely removed in one piece. Next step, an osteoplasty was held in the region to remove irregularities (Figure 6). The tumor was sent for microscopic examination (Figure 7) that showed a benign osteogenic lesion with several irregular fragments of compact bone tissue, viable, containing osteocytes 


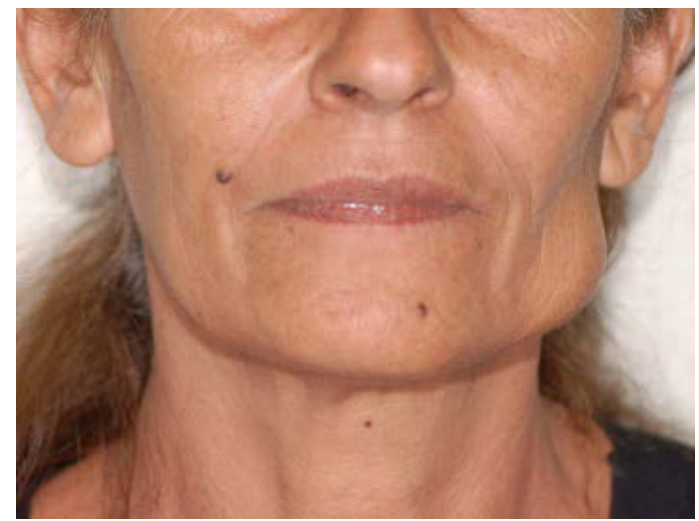

Figure 1. Clinical aspect showing facial asymmetry due to the increased mass in the left mandibular region.

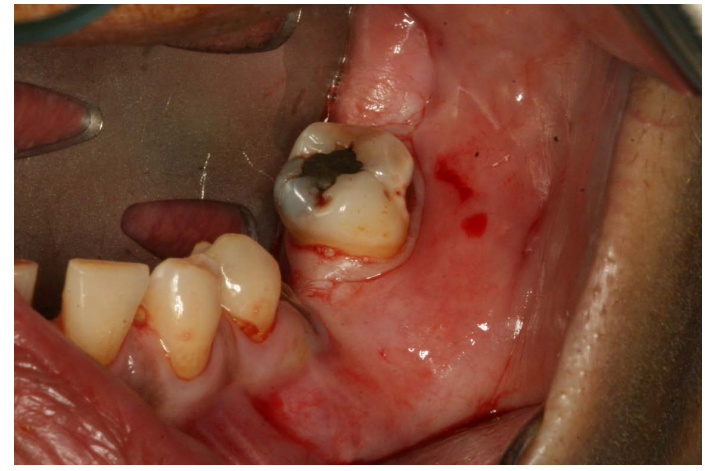

Figure 2. Intra-oral view showing increased mass covered by normal mucosa.

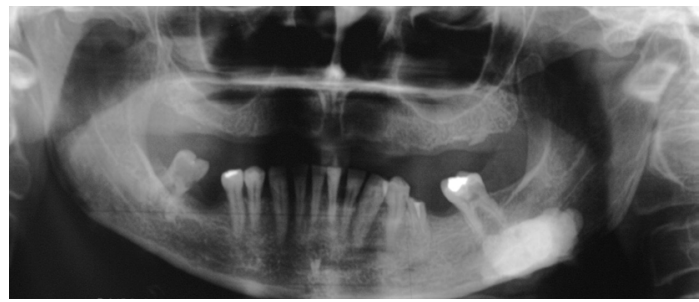

Figure 3. Panoramic X-Ray showing radiopaque image in the left mandibular region.

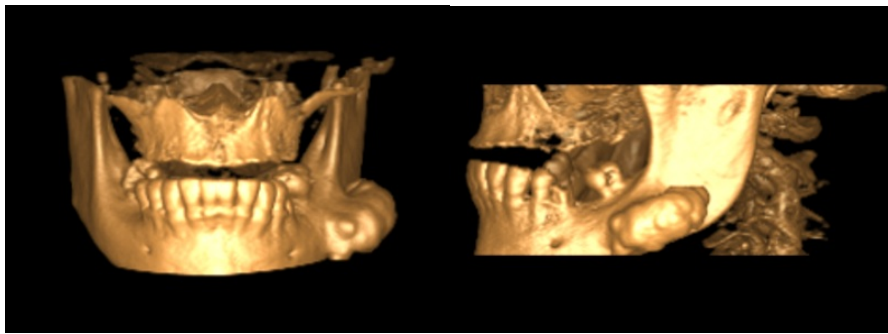

Figure 4. Three-dimensional reconstruction of cone-beam computed tomography demonstrating lobulated surface located in the left mandibular body. 


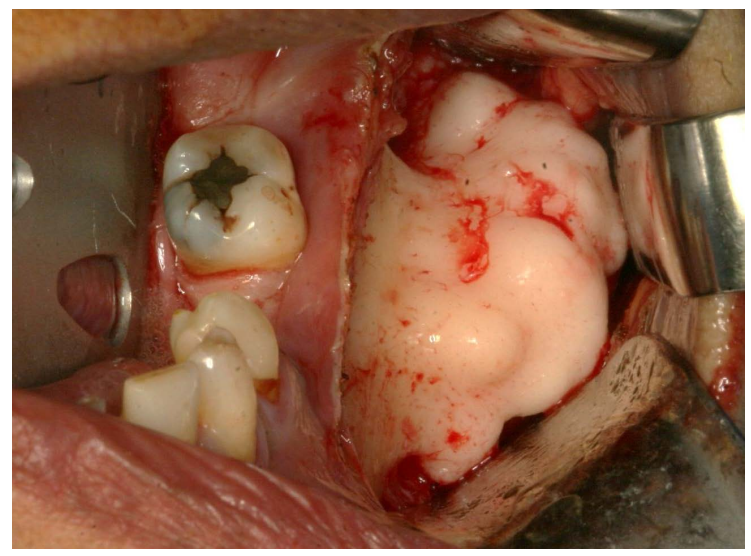

Figure 5. Intra-oral approach and exposure of the lesion.

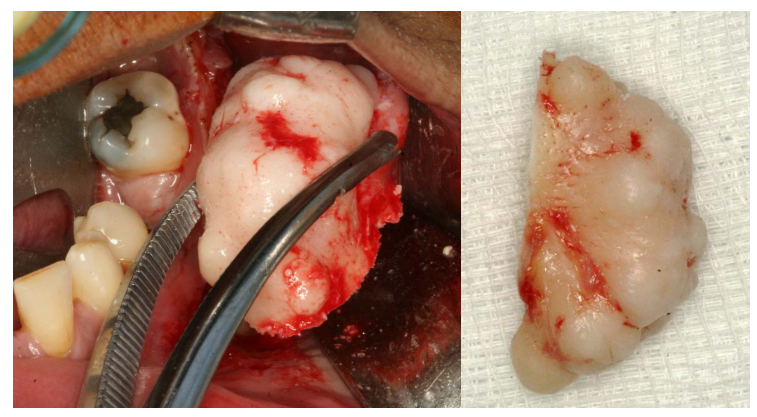

Figure 6. Lesion removal and sent to microscopic examination.

in the osteoplasts, compatible with the diagnosis of peripheral osteoma (Figure 8). The case evolved without post-operative problems and there were no signs of recurrence after 1 year follow-up (Figure 9).

\section{Discussion}

Osteoma is a benign tumour composed of compact or spongy mature bone that commonly affects the maxillofacial region (paranasal sinuses, temporal bone, sphenoid bone, external auditory canal and mandible). It is diagnosed in other bones rarely [2] [6] [7]. It can appear superficially to the bone (periosteal osteo$\mathrm{ma}$ ), which agrees with the case reported, or is still located in the medullary bone (endosteal osteoma) [1].

Osteoma presents slow growth and is usually asymptomatic in smaller cases [2] [4] [5] [6]. When it reaches large proportions, it is associated with facial asymmetry (chief complaint of the case reported), trismus, malocclusion, oral opening deviations, swallowing disorders or even breathing difficulties depending on the location of the tumour [3] [4] [5]. The majority is diagnosed after 25 years of age, and the time elapsed for its diagnosis is quite variable because it is an asymptomatic lesion causing delay to the patient to seek care [4] [5].

Several pathological entities are included as possibilities of diagnosis [9] [10]. Exostosis, for example, also presents bone growths; however, usually stops developing 


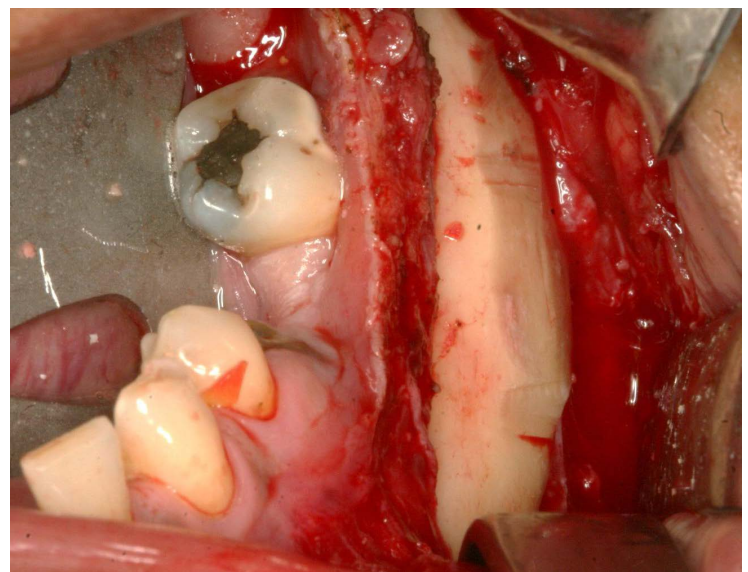

Figure 7. Aspect after osteoplastia.

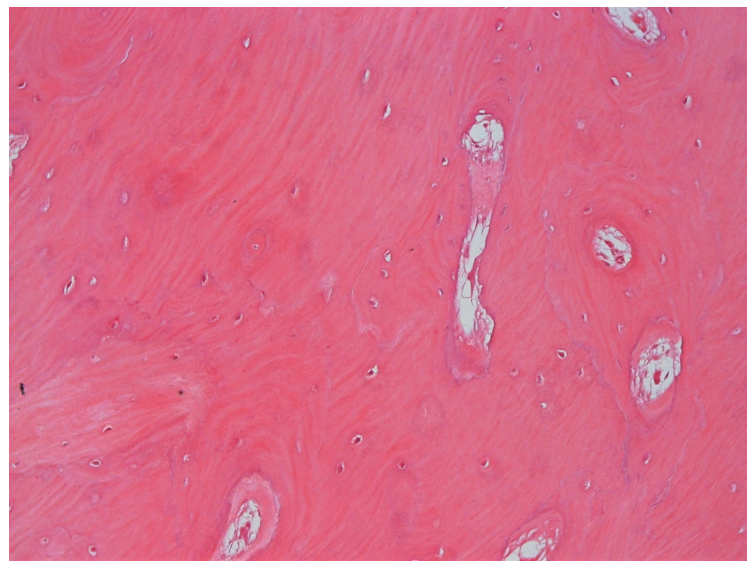

Figure 8. Benign osteogenic lesion showing several irregular fragments of compact bone tissue compatible with the diagnosis of peripheral osteoma.

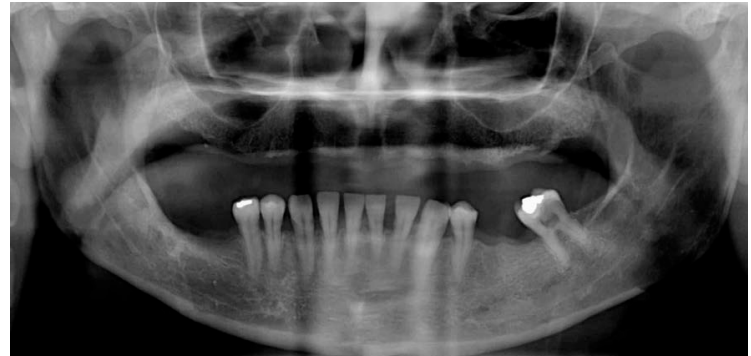

Figure 9. 1-year follow-up X-Ray with no signs of tumour recurrence.

when puberty is achieved, which is different from the osteomas [3] [9] [10]. Osteoblastomas should also be considered as hypothesis. However, rapid growth is clinically observed and they are often painful when compared to osteomas [9]. In addition, odontomas also present similar radiopacity in a radiographic examination, however, presenting greater bone density which resembles that of the tooth [9]. 
In the case of peripheral osteoma, X-Rays usually show radiopaque mass, well-circumscribed, round or oval-shaped, and focal and reactive bone formations may be observed [3] [12]. In the reported case, panoramic radiography showed a radiopaque image at the mandibular body; however the biopsy and histopathological examination of the piece is fundamental for the final diagnosis of the lesion and computed tomography is relevant not only for the diagnosis but also for the surgical planning [3] [10] [11].

In view of these tumours, it is important to investigate the association of the osteoma with Gardner's Syndrome because more than $90 \%$ of patients with this Syndrome may demonstrate skeletal abnormalities associated with osteomas [12] and intestinal polyps that can undergo malignant transformation. So the early diagnosis is important to improve the quality of life of these patients. Other signs and symptoms should also be investigated are rectal bleeding or abdominal pain [6] [7]. In the case reported this hypothesis was ruled out.

Surgical excision with complete removal of the lesion is the treatment of choice specially in larger cases [3] [4] [7] [8]. Smaller tumours are eligible for radiographic follow-up and adequate patient orientation [4]. The surgical approach (intra-oral or extra-oral) depends on the location of the osteoma however intra-oral approach offers less risk to nerve damage [5] [9] [10] and because of this such access was used for tumor excision in the case reported.

In general, the prognosis after removal of these tumours is very good and recurrence is extremely rare. There are no reports of malignant transformation [3] [10]. Although uncommon, it is necessary attention in cases of osteoma, especially with regard to the possible diagnosis of intestinal malignant lesions and also because of the possibility of psychological and/or functional disorders. Thus, it is believed that in cases such as reported, surgical excision of the lesion is the treatment of choice and it should always be associated with the prior investigation of Gardner's Syndrome and its intestinal consequences.

The analysis of this case allows us to conclude these tumours deserve attention, especially with regard to the possible diagnosis of malignant lesions of the gastrointestinal tract in the initial stage and also by psychological disorders that it can cause to the patient. In addition, when they reach great proportions, they can generate functional problems.

\section{Consent}

The patient had given his consent for this case report to be published. This Statement is in the cover of the chart at the Bauru School of Dentistry.

\section{Conflicts of Interest}

The authors declare no conflicts of interest regarding the publication of this paper.

\section{References}

[1] Green, A.E. and Bowerman, J.E. (1974) An Osteoma of the Mandible. British Jour- 
nal of Oral Surgery, 12, 225-228.

[2] Horikawa, F.K., Freitas, R.R., Maciel, F.A. and Gonçalves, A.J. (2012) Peripheral Osteoma of the Maxillofacial Region: A Study of 10 Cases. Brazilian Journal of Otorhinolaryngology, 78, 38-43. https://doi.org/10.5935/1808-8694.20120006

[3] Geron, A.B.G., Carvalho, V.A., Santos, J.L., et al. (2017) Surgical Management of Traumatic Peripheral Osteoma of the Mandible. The Journal of Craniofacial Surgery, 28, e405-e408. https://doi.org/10.1097/SCS.0000000000003769

[4] Hernando, J., Aguilar-Salvatierra, A., Leizaola-Cardesa, I.O., et al. (2018) Piezosurgery for Treatment of Large Recurrent Mandibular Osteoma. The Journal of Craniofacial Surgery, 29, e219-e211.

[5] Rodriguez, Y.B.R., Rizzo, S., Fiandrino, G., Lupi, S. and Galioto, S. (2011) Mandibular Traumatic Peripheral Osteoma: A Case Report. Oral Surgery, Oral Medicine, Oral Pathology, Oral Radiology, and Endodontology, 112, e44-e48. https://doi.org/10.1016/j.tripleo.2011.05.006

[6] Cristofaro, M.G., Giudice, A., Amantea, M., Riccelli, U. and Giudice, M. (2013) Gardner's Syndrome: A Clinical and Genetic Study of a Family. Oral Surgery, Oral Medicine, Oral Pathology and Oral Radiology, 115, e1-e6.

https://doi.org/10.1016/j.oooo.2011.10.020

[7] Cankaya, A.B., Erdem, M.A., Isler, S.C., et al. (2012) Oral and Maxillofacial Considerations in Gardner's Syndrome. International Journal of Medical Sciences, 9, 137-141. https://doi.org/10.7150/ijms.3989

[8] Ragupathy, K., Priyadharsini, I., Sanjay, P., Yuvaraj, V. and Balaji, T.S. (2015) Peripheral Osteoma of the Body of Mandible: A Case Report. Journal of Maxillofacial and Oral Surgery, 14, 1004-1008. https://doi.org/10.1007/s12663-014-0710-0

[9] Khandelwal, P., Dhupar, V. and Akkara, F. (2016) Unusually Large Peripheral Osteoma of the Mandible-A Rare Case Report. Journal of Clinical and Diagnostic Research, 10, ZD11-ZD12. https://doi.org/10.7860/JCDR/2016/21399.8807

[10] Larrea-Oyarbide, N., Valmaseda-Castellón, E., Berini-Aytés, L. and Gay-Escoda, C. (2008) Osteomas of the Craniofacial Region. Review of 106 Cases. Journal of Oral Pathology \& Medicine, 37, 38-42. https://doi.org/10.1111/j.1600-0714.2007.00590.x

[11] Boffano, P., Roccia, F., Campisi, P. and Gallesio, C. (2012) Review of 43 Osteomas of the Craniomaxillofacial Region. Journal of Oral and Maxillofacial Surgery, 70, 1093-1095. https://doi.org/10.1016/j.joms.2011.05.006

[12] Neville, B.W., et al. (2009) Patologia Oral \& Maxilofacial. 3th Edition, Elsevier, Rio de Janeiro, 652 p. 